\title{
Manuais para o ensino elementar na Bahia: recortes históricos
}

\section{Elementary teaching manuals in Bahia: historical frames}

\author{
Emília Helena Portella Monteiro de Souza ${ }^{1}$
}

\begin{abstract}
Resumo: Este trabalho se situa na área da Cultura Escrita, no viés da escolarização e de estudo da língua portuguesa. Trata de manuais usados com fins pedagógicos, do século XVI ao XIX, com enfoque no século XIX, na Bahia, com o objetivo de tornar evidentes os gêneros escolares de maior uso, como cartilhas, catecismos, manuais de caligrafia e compêndios de várias naturezas. Também se ressaltam os processos de leitura, que vigoraram nesse período, a partir de Darnton (1992). Apresentam-se excertos de Falas de Presidentes da Província e excertos de Relatórios da Diretoria da Instrução Pública do século XIX, para evidenciar o processo de distribuição de compêndios às escolas elementares, e o que os estudantes liam. Dos manuais de ensino elementar que tiveram lugar no século XIX, na Bahia, escolheu-se a gramática de Martagão, para tecer breves comentários: verificar a concepção de língua existente, como a gramática se organiza em suas partes constituintes, como o autor percebe alguns fatos linguísticos.
\end{abstract}

Palavras-chave: Cultura Escrita; Manuais escolares; Bahia; Século XIX.

Abstract: This work situates itself in the History of Writing Culture having the schooling process and the studing of Portuguese as its background. It deals with teaching manuals adopted for pedagogical purposes between the 16th and 19th centuries and focuses on 19th century Bahia. Its objective is to point out the mostly used teaching materials such as primers, catechisms, handwriting manuals as well as books of varied nature. This work also aims at the reading processes in use during this time frame as highlighted by Darnton (1992). In order to evince the distribution process of handbooks among elementary schools in Bahia and what students read we show some 19th century excerpts of both the Provincial President's speech and of the Public Instruction Director's Reports. Of the elementary teaching manuals adopted in 19th century Bahia we chose Martagão's grammarbook about which we make a few brief comments as regards how "language" is conceived, how his grammarbook is divided, and how its author addresses some linguistic facts.

Keyword: Writing Culture; School manuals. Bahia. 19th century.

\footnotetext{
${ }^{1}$ Programa de Pós-Graduação em Língua e Cultura (PPGLinC) - UFBA. E-mail: emiliahelena.pm@gmail.com
} 


\section{Introdução}

Neste texto, vai-se tratar sobre o livro didático numa perspectiva histórica. Será feito um breve apanhado a respeito do que era usado como manuais de ensino pelas escolas de primeiras letras, em especial na Bahia, com enfoque no século XIX. Nesse século, houve uma diversidade de livros destinados ao ensino, para exercício da leitura, para aprendizagem da língua, para doutrinação religiosa, para formação moral. A grande maioria dos livros foi comprada pela província, outros foram doados. Também coube à província fazer a distribuição às escolas. Fizeram parte desses livros escolares, gramáticas.

Na primeira metade do século e ainda adentrando a segunda metade, predominaram as gramáticas filosóficas, algumas voltadas para o ensino elementar, outras para níveis mais adiantados. Como os livros de leitura, caligrafias, ortografias, nem todas as gramáticas que circularam nas escolas baianas foram conservadas. Muitas foram produzidas por professores baianos, que, para serem adotadas, tinham que ser submetidas ao Conselho da Instrução Pública. Uma dessas gramáticas é a de Bernardino Martagão, voltada para o ensino elementar, e usada na primeira metade desse século na Bahia. Um exemplar dessa gramática encontra-se no setor de obras raras da Biblioteca Universitária Reitor Macedo Costa da Universidade Federal da Bahia. Propõe-se, neste texto também, apresentar essa gramática, em termos de suas partes constituintes, e tecer algumas considerações.

\section{Compêndios, manuais e a leitura nos séculos recortados}

O termo "livro didático" só vai aparecer, pela primeira vez, no Decreto Lei no 1006, de 30 de dezembro de 1938, Artigo 20, Parágrafo $1^{\circ}$. (OTA, 2009). Antes disso, têm-se os compêndios, os manuais, os livros de leitura, as cartilhas, os catecismos e livros diversos voltados para a educação moral e religiosa. Alguns livros não são propriamente escolares, mas são usados pela escola, em conformidade com as concepções da época, do ponto de vista sociocultural e educacional; também, porque não existiam mesmo obras, eminentemente escolares, principalmente até a primeira metade do século XIX. A imprensa no Brasil é tardia. Só é instalada a partir da chegada de D. João, em 1808.

Chartier (2016, p. 37) dá uma ideia de como as obras, os leitores e a leitura se conformam de acordo com o seu tempo.

[...] os enfoques que interpretaram a leitura como uma "recepção" ou uma "resposta" universalizaram implicitamente o processo da leitura, considerando-o como um ato sempre similar cujas circunstâncias e modalidades concretas não importam. Contra "esse desbotamento" da historicidade do leitor, convém recordar que a leitura também tem uma história (e uma sociologia) e que o significado dos textos depende das capacidades, das convenções e das práticas de leitura próprias das comunidades que constituem, na sincronia ou na diacronia, seus diferentes públicos. (CAVALLO; CHARTIER, 1995; BOUZA, 1999).

A leitura, como os leitores, tem a sua historicidade, e o significado dos textos vai estar diretamente ligado à comunidade que os lê, em suas diferentes temporalidades. É nessa perspectiva que as obras, os leitores e as leituras vão ser percebidos, nos séculos contemplados. 
Foram muitos os gêneros escolares, ou gêneros que se prestaram como tal, que foram destaque do século XVI ao XIX, salientando-se o século XIX na Bahia. Alain Choppin (2009) faz uma interessante discussão sobre os livros que circularam nas escolas, com o propósito pedagógico. Segundo Choppin, são muitas as denominações usadas para esses manuais escolares, e uma forma de classificá-los é de acordo com sua função. Por exemplo, alguns fazem referência à sua organização interna, principalmente quando se referem a um conjunto de textos, em português, antologia; italiano florilégio etc.; outros designam sua função sintética, português, compêndio; ou seu papel diretivo - guia ex.: guia prático; outros ainda evocam o método de aprendizagem, método Castilho; outros a alternância de questões e respostas, espanhol, catecísmo; ou a exposição organizada, do simples ao complexo, francês, rudiments, espanhol, nociones, inglês, elements etc. Choppin chama atenção para o fato de que essas denominações não são específicas das línguas vernáculas, elas remontam aos títulos do grego e do latim, por exemplo: epítome em grego; em latim: epitome, compendium, selecta, rudimenta, janua, introductio. A maioria dessas denominações é usada pelos vernáculos e são muito familiares, nos títulos dos livros, especialmente do século XIX: livros de leitura, gramáticas, livros religiosos da doutrina cristã etc.

Sobre os manuais, Choppin (2009, p. 22) diz que na França utilizam, indiferentemente, manue/s scolaires, livres scolaires ou livres de classes, os lusófonos usam livros didáticos, manuais escolares ou textos didáticos. Numerosas expressões levam em conta a forma do material, em formato pequeno, que temos a mão ou que levamos na mão, daí manuais escolares; outras expressões remetem ao texto, textos didáticos, texto escolar, livro de texto. 0 autor esclarece que o manual se impôs no mundo pelo viés da evangelização e da colonização. (CHOPPIN, 2009, p. 28)

Do século XVI ao século XVIII, estendendo-se à primeira metade do século XIX, existiam as cartilhas e os catecismos, usados para a aprendizagem da leitura e da escrita, sendo que a cartilha permanece com essa função por praticamente todo o século XX. Segundo Choppin (2009, p.17), "A denominação pode então refletir as características materiais, como no caso da cartilha - cartilla, hornbook, do battledore ou da palette."

O termo "cartilha" é proveniente de cartinha, pois inicialmente ensinamentos do alfabeto e da doutrina cristã vinham em forma de cartas. Essa se difundiu na Europa, no século XVI. A cartilha apresenta as letras do alfabeto e os primeiros rudimentos da aprendizagem da leitura. Frequentemente, contém a doutrina cristã, orações, os mandamentos etc. É um pequeno livreto. As cartilhas do século XVI constam de uma simples folha (carta) impressa que, dobrada duas ou três vezes, forma um caderno in-40 ou in- $8^{\circ}$, com oito ou dezesseis páginas. A cartilha se popularizou na Península Ibérica e na América Latina. (CHOPPIN, p. 18).

Quanto ao horn-book, ou hornbook (italiano tavola; espanhol, tableta), esse se originou na Inglaterra, na Idade Média. Não se trata de um livro, propriamente, mas de uma folha de papel nobre a qual são reproduzidos o alfabeto, a oração do Pai Nosso, ou ainda os números de 1 a 10... Choppin (p. 18) esclarece que "Em inglês, o nome deriva dessa folha, montada sobre um pedaço de madeira ou de couro, de formato reduzido e emoldurado com madeira ou metal, estando protegido por uma fina película de chifre (horn)." Provavelmente, seja um antecedente histórico da cartilha.

No século XVI, tem-se a famosa cartinha de João de Barros (1539), um dos primeiros gramáticos portugueses, do início dos tempos modernos. Desde o final do século XV e por todo o século XVI, com a expansão marítima portuguesa, indo até a Ásia, África e América e criando as possessões de ultramar, que 
se enviam cartilhas ou cartinhas. Américo Cortês Pinto (1948, p. 238) diz que Portugal foi o primeiro país que imprimiu cartilhas de $A B C$, para ensinar os povos africanos e asiáticos. Essas se constituíam de duas partes, uma parte com os rudimentos de ensino da língua, o alfabeto, as sílabas e alguns nomes, e a outra parte, a maior, com os preceitos da doutrina cristã. Atendia-se, assim, ao ensino da língua portuguesa e à cristianização dos povos "bárbaros". A cartinha de João de Barros, Cartinha com os preceitos e Mandamentos da Santa Madre Igreja a mais famosa, tem uma sofisticação maior, considerando-se a exploração dos recursos visuais. É um livreto composto por 28 fólios, dos quais oito (8) são dedicados ao ensino das letras e da leitura, e vinte constam das orações. A letra que inicia cada oração vem em destaque. "Entre letras e orações: aprende-se, ao mesmo tempo, a pronunciar as letras e a rezar". (MARIGUELA, 2011, p. 150).

Durante o século XVI e o século XVII se "alfabetizou" utilizando-se dessas cartilhas e dos catecismos. O catecismo se popularizou a partir do século XVI, ao ser impresso nas línguas vernáculas europeias, sendo essa uma decisão do Concílio de Trento (1545-1563). (BARROS, 2001, p.28).

As cartilhas tiveram uma vida longeva, considerando-se que desde o século XVI foram usadas, em Portugal e em suas colônias. Até o século XIX, as cartilhas se alternaram com os catecismos $_{L}$ na função da aprendizagem da leitura e da doutrina cristã. As cartilhas perduraram até o século XX. $O$ catecismo tinha também a função não só de ensinar a doutrina cristã, visando à evangelização, mas também servia para a aprendizagem da leitura. Muitos foram os catecismos distribuídos, nas colônias portuguesas, a partir do século XVI, sendo muitos deles traduzidos para os vernáculos, para que a ação evangelizadora fosse mais eficiente.

Destaca-se dos conhecidos catecismos, o de Montpellier, ou mais propriamente o catecismo da Diocese de Montpellier, pelo bispo Charency. Esse concorreu com o catecismo de Fleury - bastante usado nas aulas públicas primárias - no século XIX. ${ }^{2}$ Segundo Tambara (2002, p. 40), o catecismo de Montpellier foi traduzido para o português ainda no século XVIII, "foi o instrumento de doutrinação religiosa que com maior intensidade foi utilizado em sala de aula." Tambara acrescenta sobre a natureza dessa obra: "Como outras obras desse gênero, em determinadas edições foram agregados conteúdos de outra índole. Como atesta o reclame da primeira edição da Laemmert no Brasil". (p. 40) Nesse reclame, é dito que nesta "novíssima edição" foram acrescentados: um Compendio da Orthographia Portugueza, um resumo de Arithmetica e um tratado de Geographia Universal. (LAEMMERT, 1862).

Esse catecismo de Montpellier, durante certo tempo, foi o único compêndio usado, segundo as pesquisas de Trindade (2018), no Recolhimento de Nossa Senhora dos Humildes, em Santo Amaro da Purificação - Bahia, no século XIX, no seu Educandário. Presume-se que tenha sido adotada essa edição, com acréscimos de Ortografia, Aritmética e Geografia, além da doutrina cristã. A doutrina cristã é estudada em forma de diálogo, pergunta e resposta. Essa prática remonta aos gregos, mas foi retomada no século XVI, a partir de Lutero, com os catecismos protestantes. Depois da introdução desses impressos, a igreja católica também o instituiu. Segundo Orlando (2013, p. 162), o catecismo "Organizado em formato de perguntas e respostas, uma novidade no século XVI, visava a transmitir a mensagem e ensinar pelo diálogo os valores e as normas da igreja."

Com as licenças necessárias, esta edição não contém os anexos referidos.

\footnotetext{
${ }^{2} \mathrm{O}$ catecismo de Montpellier foi impresso e publicado pela primeira vez em 1702. O catecismo de Fleury, do padre e escritor francês Claude Fleury, foi publicado pela primeira vez na França, em 1679. (CHOPPIN, p. 40).
} 
No século XIX, foram usados não só o catecismo de Montpellier, e o de Fleury, mas outros, como do Bispo do Pará ${ }^{3}$ que, de certa forma, aliavam o ensino da doutrina e a aprendizagem da leitura, via memorização. Só mais para o final do século, com o método intuitivo, ou "lições de coisas", é que a aprendizagem se distanciou da memorização.

A história do livro e a história da leitura se entrelaçam. O livro é um artefato cultural, que se apresenta com as características das sociedades em que ele circula, em cada momento histórico, constituindo, a partir dele, a história das leituras e dos leitores. Como liam as sociedades pretéritas?

Segundo está em Adriana Mariguela (2011, p. 150)4, "[...] é preciso entender o sentido de ler, na época de João de Barros, ao se considerar os métodos escolásticos e humanistas. 'Ler, etimologicamente, é 'ler em voz alta', recitar, declamar, recolher, apanhar, enrolar, captar com os olhos, alude à apreensão de um conhecimento e não propriamente à alfabetização." É estabelecida uma relação entre o ato de leitura e a apreensão do conhecimento, tornado possível pela memorização. É assim que se aprendiam os preceitos da doutrina cristã e o latim. Era fazendo uso dessa metodologia que os jesuítas ensinavam a doutrina cristã na catequese, e que, de certa forma, predominou, como processo de ensino aprendizagem, ainda nos séculos XVIII e boa parte do XIX. Esse tipo de leitura estava longe de ser uma leitura funcional.

Darnton (1992), tratando sobre as diversas formas de se fazer leitura, diz ser esta não apenas uma habilidade, mas uma forma de estabelecer significado, devendo variar de cultura para cultura. Sobre a leitura nos séculos XVI e XVII, Darnton diz que essa "foi encarada acima de tudo como um exerć́cio espiritual" (DARNTON, 1992, p. 218). Aludindo à Bíblia, diz ser esta abordada com temor, tanto para católicos quanto para protestantes, sendo a leitura vista como uma atividade sagrada para a maioria das pessoas. "No tempo de Lutero e Loyola, a leitura promovia o acesso à verdade absoluta." (DARNTON, 1992, p. 220). Pode-se dizer que Lutero promoveu primeiramente esse acesso, nos tempos modernos, considerando-se que a Bíblia foi passada do latim para o vernáculo, ele mesmo a traduziu para o alemão, para que o homem comum, o povo, pudesse ter acesso às escrituras.

Sobre a leitura no século XVII, na Europa, Darnton (1992, p. 221) traz informações interessantes sobre essa atividade na Inglaterra e na França. Parte da seguinte pergunta: "Mas como liam os leitores comuns?" O autor apresenta algumas sugestões para se investigar sobre essa atividade. Uma delas é que se verifiquem as maneiras como a leitura era ensinada. Na Inglaterra, pesquisas realizadas por Spufford, segundo Darnton (1992), revelam que grande parte do aprendizado ocorria fora da escola, esse era realizado nas oficinas e nos campos, onde os trabalhadores ensinavam a si mesmos e aos outros. As crianças aprendiam primeiramente a ler, depois é que aprendiam a escrever. Na França do Antigo Regime, as cartilhas mais comuns começavam como os manuais modernos, com o alfabeto. As letras "eram consideradas como estímulos visuais para acionar a memória de um texto que já havia sido aprendido de cor - e o texto era sempre em latim". As crianças passavam "diretamente do alfabeto para sílabas simples e daí para o Pater Noster, a Ave Maria, o Credo e o Benedicite. Tendo aprendido a reconhecer essas orações comuns, passavam para as respostas litúrgicas impressas nas brochuras padronizadas". (DARNTON, 1992, p. 222). Como o aprendizado era em Latim, primeiramente, muitas crianças permaneciam na escola para aprender a ler em francês. Mesmo assim, diz o autor, a leitura era uma questão de reconhecimento de algo já conhecido, em vez de um processo de aquisição de um novo

\footnotetext{
${ }^{3}$ O Cônego Fernandes Pinheiro, autor do Catecismo de Doutrina Cristã. Esse catecismo foi impresso por ordem do Exmo. e Revmo. Sr. Bispo do Rio de Janeiro para uso de sua diocese, adaptado pelo Exmo. e Revmo. Sr. Bispo do Pará.

${ }^{4}$ Mariguela (2011) se reporta a Le Dü Silva (2003, p. 22).
} 
conhecimento. Quase todas as escolas eram orientadas pela igreja, e quase todos os livros didáticos eram religiosos, em geral catecismos e livros de devoção. Essa realidade não é diferente da que existiu em Portugal e em suas colônias, haja vista a experiência que se teve com os jesuítas (1549-1759), e que permaneceu depois da expulsão deles, adentrando o século XIX.

Segundo Darnton (1992, p. 223), no século XVIII, nas famílias aristocráticas, os preceptores ensinavam as crianças a ler diretamente em francês. A maior parte das crianças

[...] aprendia a ler, ficando de pé diante do professor e recitando passagens de seja de qual fosse o texto em que conseguissem pôr as mãos, [...]. Alguns desses 'livros didáticos' iriam reaparecer à noite na vieillé, porque eram livros populares muito vendidos na bibliothèque blue. Portanto, a leitura ao pé do fogo tinha algo em comum com a leitura em uma sala de aula: era uma récita de um texto que todos já conheciam. (DARNTON, 1992, p. 223).

O que se depreende dessa passagem é que não havia, nesse período, uma separação entre os "livros didáticos", aqueles de uso na escola e os livros que eram lidos popularmente; também como se dava a leitura, uma récita de um texto conhecido! Assim foi também aqui no Brasil.

No século XVIII, entram em cena os manuais de caligrafia, para a aprendizagem da escrita. Esses manuais de caligrafia eram vistos como cartilhas, pois esses além de conter instruções fundamentais para o aprendizado da escrita, neles se podia também encontrar ensinamentos sobre aritmética e religião. (SOUZA, 2012, p. 21). Embora em Portugal o primeiro livro de caligrafia registrado seja do século XVI, só no início do século XVIII é que uma maior atenção é dada à caligrafia, com a publicação de a "Nova escola para aprender a ler, escrever e contar" do jesuíta Manoel de Andrade de Figueiredo (1722). ${ }^{5}$

Diz Souza (2012) sobre os manuais de caligrafia do setecentos:

\begin{abstract}
Em nível de conteúdo, o próprio título dos manuais evidenciavam os assuntos a serem estudados, e que constituíam, à época, as matérias básicas do ensino elementar: ler, escrever e contar. A esses conteúdos acrescentavam-se normas de civilidade e doutrina cristã, cabendo ao próprio calígrafo o domínio desses conteúdos, bem como a pedagogia para transmiti-los aos aprendizes. (SOUZA, 2012, p. 25)
\end{abstract}

Ao longo do século XVIII, foram os calígrafos muitos dos responsáveis pelo ensino das primeiras letras e por isso eram considerados mestres de ler, escrever e contar. Souza (2012, p. 29) diz que há estudos que comprovam que, no início do século XVIII, no Brasil, nas capitanias mais desenvolvidas como Minas, Bahia, Pernambuco e Rio de Janeiro, havia escolas de ensino elementar que funcionavam sem a subvenção do governo, os professores eram pagos pelos pais, ou pela comunidade das vilas em que essas escolas estavam implantadas. Os calígrafos atuavam como mestres do ensino elementar.

Referindo-se à obra de Figueiredo, Silva (2002, p. 1) afirma que alguns professores régios na capitania da Bahia o possuíam. Essa "foi citada em um número razoável de testamentos e inventários".

No século XIX, se mantém esta cultura manuscrita. Os alunos entravam em contato com diferentes formas de letras para se exercitarem na leitura. Ao lado dos poucos livros que circularam na escola, na primeira metade do século XIX, e em maior quantidade na segunda metade, estavam os

\footnotetext{
${ }^{5}$ Figueiredo nasceu no Brasil, em 1670, estudou teologia na Universidade de Coimbra. Ordenado Padre, ficou conhecido em Lisboa como pedagogo e um dos principais mestres de leitura, de escrita e de aritmética. Sua obra foi indicada para uso nas aulas régias de primeiras letras do reino português, durante e após o período pombalino. (SILVA, 2002, p.2).
} 
manuscritos. Os livros manuscritos ou paleógrafos perduraram durante todo o século XIX e mais da metade do século XX. Predominaram, como manuscritos, para uso de leitura corrente, contratos, certidões, cartas, ou os livros de leitura manuscrita. (BATISTA, 2002).

Sobre os compêndios, Choppin (2009, p. 32) diz que são "obras inspiradas nos tratados científicos, mas com o objetivo de assegurar a vulgarização dos conhecimentos". Em um sentido, no caso da França, os compêndios seriam "protomanuais".

No século XIX, principalmente na primeira metade, o que se observa, nos Relatórios dos Diretores da Instrução Pública, ou na Fala dos Presidentes da Província, é o uso indiscriminado da palavra compêndio. Assim é que na Fala do Presidente da Província, João José de Moura Magalhães, à Assembleia Legislativa, em 1848, tratando das aulas elementares, diz que estão em mau estado, devido à ignorância e negligência dos professores, pela falta de compêndios e utensílios, de unidade e de uniformidade do ensino "tudo concorre para esse deplorável atraso, em que ainda se acha a instrução elementar." (MAGALHÃES, 1848, p. 9). O uso de compêndio é para se referir aos livros como um todo. Nesta mesma fala, diz: "Mandei admittir para o uso das Escolas o Cathecismo Historico de Fleury, compendio de sabido merecimento [...]"(MAGALHÃES, 1848, p. 12). O uso de compêndio é para se referir ao catecismo.

Em 1850, na fala do Presidente da Província, Francisco Gonçalves Martins, é dito que: "[...] 0 Conselho de Instrucção Publica pedindo approvação e impressão de varios compendios para uso das escolas" (MAGALHÃES, 1848, p. 12). Uso da palavra compêndio para se referir a livros, em geral.

No ano de 1854, no Relatório de Casimiro de Sena Madureira: "Não foram ainda entregues à direção dos estudos para a distribuição dos compendios de calligrafia de Wanzeler, mandados imprimir a dous annos por ser o author approvado pelo Conselho de Intrucção Publica. Esta falta se tem feito muito sensível pois que não há outro que a remedee" (MADUREIRA, 1854, p.10). Como visto, o significado da palavra compêndio tem um uso mais alargado, do que foi proposto por Choppin.

Na segunda metade do século, embora ainda se utilize com frequência a palavra compêndio, essa concorre com a palavra livro, nos documentos oficiais. No Relatório de 1872, do Diretor da Instrução Pública, Dr. Francisco José da Rocha, referindo-se aos problemas da falta de mobília apropriada, de bancos, utensílios e também de livros, nas escolas públicas, diz:

\footnotetext{
São uteis e necessarios os livros, mas a creança não fará d'elles uso proveitoso sem esses outros meios de commodidade e de applicação, e até em algumas classes, em algumas idades, os livros poderiam ser temporariamente dispensados, e vantajosamente substituídos pelas lições dos objetos, pela construção mental da syllaba, de palavras, de phrases, como se procede nas escollas mais adiantadas da America do Norte [...] (ROCHA, 1872, p. 5).
}

Interessante que, neste início do decênio de 70, o Diretor da Instrução Pública, além de tratar dos livros, faz referência ao método de ensino, que irá predominar no final do século XIX, que é o intuitivo, ou "lições de coisas."6 Nesse mesmo Relatório, (ROCHA, 1872, p. 36) há uma relação de livros sob o título "Distribuição de livros pelas escholas publicas primarias".

Na Fala do Presidente da Província, Antonio Candido da Cruz Machado, 1874, faz referências à compra de livros: "Compraram-se durante o anno os seguintes livros".

\footnotetext{
${ }^{6}$ A obra Lições de coisas foi escrita pelo americano Norman Alisson Calkins (1861), e teve a tradução de Rui Barbosa (1886).
} 
No Relatório de 1876, do Diretor da Instrução Pública, Dr. José Eduardo Freire de Carvalho (p.12) está dito: "Os livros distribuídos pelas escholas publicas tem sido os approvados pelo Conselho Superior de Instrucção Publica."

O que fica evidente nesses excertos de Falas de Presidentes da Província e dos Relatórios do Diretor da Instrução Pública não é apenas a utilização dos léxicos compêndios e livros, mas uma dinâmica em relação à aprovação, impressão e distribuição de livros às escolas públicas, e o estado em que essas se encontram, em relação à educação.

\title{
Distribuição de livros às escolas públicas. A gramática de Bernardino Martagão
}

Além de material manuscrito, na primeira metade do século XIX, a aprendizagem da leitura se dá em cartilhas, nos abecedários, silabários, catecismos, livros de moral cristã etc.. Muitos são os livros que não tinham uma função pedagógica, mas foram usados como tal. É o que se percebe a partir da relação de livros que eram distribuídos na escola de ensino elementar, na Bahia. Sabe-se que eram distribuídos, mas não há informação segura de quanto desses existiam de fato em uso na sala de aula. Em algumas Falas ou Relatórios, são apresentados os livros e o quantitativo que, ou foram distribuídos nas escolas, ou serão distribuídos.

Como no Relatório do Presidente de Instrução Pública, Dr. Justiniano da Silva Gomes endereçado ao Presidente da Província, Francisco José de Sousa Soares d'Andrea, no ano de 1846, em que diz que o governo comprou cem exemplares dos primeiros cantos da Eneida pelo professor João Gualberto e incumbiu ao Conselho a distribuição, "[...] que a tem feito pelos professores e estabelecimentos a que essa leitura instruísse." (ANDREA, 1846, p. 6).

Na Fala do Presidente da Província João José de Moura Magalhães, em 1848, à Assembleia Legislativa, esse faz referência à compra do Catecismo de Fleury e do Manual Enciclopédico de Monte Verde ${ }^{7}$ :

\begin{abstract}
Mandei admittir para uso das escolas o Cathecismo Fleury compendio de sabido merecimento, e muito apropriado à pequena capacidade dos alumnos, tendo sollicitado do Governo Imperial 200 exemplares, que com a maior benevolência m'os remetteo, e por intermédio do mesmo Governo pedi que effetuasse em Lisboa a compra de trezentos exemplares do Manual Encyclopedico de Monte Verde, que a Lei Provincial no 127, com acertada escolha, determinou que fosse admittido nas Aulas primárias. Por aviso do Ministerio do Imperio de 3 de fevereiro do corrente anno sei que esta encommenda foi feita à nossa Legação em Lisboa. (MAGALHÃES, 1848, p. 12-13)
\end{abstract}

Em 1854, o Relatório da Directoria Geral de Instruç̧ão Publica, de Casimiro de Sena Madureira, quando trata dos compêndios, faz referência à reimpressão do catecismo histórico de Fleury e diz ser "distribuído gratuitamente pelos alumnos das escolas publicas primarias e o Folheto da Sciencia do Bom Homem Ricardo8, que eh optimo compendio de leitura para os principiantes." (MADUREIRA, 1854, p.8).

\footnotetext{
${ }^{7}$ Emílio Aquiles Monteverde. (1803-1881) português de origem, escreveu o Manual Encyclopedico, que foi amplamente adotado na Bahia, e em outras províncias, nas escolas.

8 "A Sciencia do Bom Homem Ricardo, ou meios de fazer fortuna" foi escrito pelo americano B. Franklin. Traduzido em Lisboa, Typ. Soc. Propagadora dos Conhecimentos Uteis, 1825.
} 
O Relatório de 1872 apresenta a distribuição de livros pelas escolas primárias. Na relação, há uma coluna do número do que foi distribuído e outra do número dos que existem. São, ao todo, 23, mas serão apresentados apenas 10, como no quadro 1.

Quadro 1: Distribuição de livros pelas escolas públicas.

\begin{tabular}{|l|c|c|}
\hline \multicolumn{1}{|c|}{ Livros } & Distribuíram-se & Existem \\
\hline $1^{\circ}$ Livro de Leitura de Abílio César Borges & 2.100 & 191 \\
\hline $1^{\circ}$ Livro de Leitura de Manoel Jesuíno & 894 & 16 \\
\hline $2^{\circ}$ Livro de Leitura de Manoel Jesuíno & 1.980 & 1.702 \\
\hline Grammatica de Manoel Agostinho & 881 & - \\
\hline Grammatica de Latino Coelho & 798 & 1.804 \\
\hline Desenho linear & 1.467 & - \\
\hline Calligraphias & 1.035 & 2179 \\
\hline Bom Homem Ricardo & 2997 & 479 \\
\hline Cartas de ABC & 3445 & 1262 \\
\hline Orthographia de Araponga & 2125 & \\
\hline
\end{tabular}

Fonte: Relatório do Diretor Geral da Instrução Pública, Dr. Francisco José da Rocha (1872)

Observe-se que, além dos que são distribuídos, ainda há estoque. No Relatório dDr. Francisco José da Rocha, Diretor Geral da Instrução Pública 1872 (p. 37) há essa mesma distribuição para as escolas noturnas. As aulas noturnas são para adultos, e são praticamente os mesmos livros do curso elementar para as crianças.

O Brasil teve uma imprensa tardia. A partir de 1808, com a chegada de D. João e sua comitiva, foi criada a imprensa régia. A princípio a imprensa atendia somente aos atos e resoluções do governo imperial. Os livros que eram usados nas escolas de primeiras letras vinham de Portugal, ou eram produzidos por autores portugueses ou eram traduzidos, principalmente, da França. No início do século XIX, a impressão de livros escolares se dava no Maranhão, Minas Gerais e Pernambuco. No final do século, muitas províncias tinham já consolidado o seu sistema editorial de livros didáticos autônomos, como a Província de São Pedro do Rio Grande do Sul, o Rio de Janeiro etc. (TAMBARA, 2002, p. 30-32).

Quanto aos manuais que seriam adotados, as escolas ficavam sempre sujeitas ou à doação, ou ao envio, pela Assembleia Provincial, apenas daqueles que eram aprovados. Na verdade, não existiam livros em quantidade, e se criticava muito o ensino individual, pois não havia uniformidade das obras que eram usadas nas atividades escolares.

No que tange às doações, Jesus (2018) trata sobre doações de livros às escolas públicas, e verifica que muitas das correspondências sobre doação não eram de doação, mas eram ofertas de livros, por seus autores, para serem comprados. Como tinham que ser avaliados pelo Conselho da Instrução Pública, muitos não eram aceitos. 
Seguem duas dessas correspondências, disponíveis no Arquivo Público do Estado da Bahia (APEB), Seção de Arquivo Colonial e Provincial, que foram editadas por Jesus (2018). A primeira dessas correspondências, abaixo, trata da questão dos livros que são distribuídos e que nem sempre chegam em quantidade às escolas. A segunda correspondência trata de livros que seriam vendidos, mas não são aceitos pelo Conselho.

Transcrição 1 (JESUS, 2018, p. 79)

Ill(ustríssi)mo Ex(celentíssi)mo S(e)n(hor)

Constando-me que por conta do Gov(ern)o,

e $\mathrm{p}(\mathrm{ar}) \mathrm{a}$ se distribuírem pelas Escholas

Primárias se comprarão m(ui)tos exemplares

do Pequeno Cathecismo Histór

ico de Fleury, obra adoptada

como Compendio desta Escola,

e de que se não podem prover os

Alumnos por não existir a venda

nesta Prov(ínci)a, vou rogar a V(ossa) Ex(celênci)a

que daquelles exemplares, deposi

tados em mão do Presidente do

Conselho de Instrucção Publica,

mande pôr à minha disposiç

ão 20 , sem os quaes he impos

sivel continuar o ensino nesta

parte.

D(eus) G(uard)e a V(oss)a Ex(celênci)a Acta da Escho

la Normal 2 de $\mathrm{Ag}$ (os)to 1848

Ill(ustríssi)mo Ex(celentíssi)mo S(e)n(ho)r Conselheiro Presidente da Pro(vínci)a

João Al(ve)z Portella

Transcrição 2 (JESUS, 2018, p.75):

Em resposta ao officio de

$\mathrm{V}$ (ossa) Ex(celênci)a com data de 10 do cor-

rente mez, tem o Conselho

a honra de informar a V(ossa) Ex(celênci)a,

que não approva para uso

das respectivas Aulas da Pro-

víncia, o Compendio de Geo

graphia do $\mathrm{D}$ (outo)r Thomaz Pom

peo de Souza Brazil.

$D$ (eu)s Guarde a V(ossa) Ex(celeênci)a Sala

do Conselho da Instrucção

Publica 12 de 8bro [outubro] 1853

Ill(ustríssi)mo e Ex(celentíssi)mo S(e)n(ho)r Presidente

da Província

João Ant(ônio) de Vascon(celos)

Presidente

Há uma lista de obras que foram liberadas e distribuídas nas escolas de primeiras letras, pela Assembleia Legislativa da Bahia, no ano de 1848. Algumas dessas obras tiveram uma longevidade no seu uso, na província da Bahia.

Transcrição 3 (JESUS, 2018, p. 87):

Livros que a Assembleia Legislativa da Provincia ou o Governo tem mandado distribuir pelas Escolas da Província 
Cathecismo de Montpellier

Cathecismo historico de Fleury (edição da B(ahi)a e do Rio)

Sillabarios, maximas e taboadas em quadros in folio

Escola Brasileira de Cairú

Curso normal do Barão Degerando

Simão de Nantua

Manual enciclopédico de Monte Verde

Deos e a Sociedade, com hum compendio appenso de arithimetica

Compendio de Theologia exegetica trad(uzido) p(elo) P(adr)e Cajueiro

Ensaio sobre a Constituição Divina da Igreja traduzido $\mathrm{p}$ (or) [...] Mariano

$01^{\circ}$ Volume da Eneida de Virgilio; traducção do Professor João Geralberto Há dous exem-

plares em [...]; a traducção completa já publicada consta de 3 vol(umes)

Bom homem Ricardo, de Franklin.

Além destes, são ainda admittidos nas Escolas os seguintes:

Grammatica Portugueza por Figueiroa

Grammatica de Pedro José de Figuerêdo

Desenho Linear, de Gentil

Cathecismo de Montpellier, edição de Paris que contem huns compendios de Ortographia, de arithmetica e de

Geographia

Thesouro da Mocidade

Leituras juvenis

O amigo dos Meninos

$O 1^{\circ}$ Volume da educação familiar de Mies Edgessorth tradução do $D$ (outo)r Paulo Araujo

Leções de hum pae à huã filha, por Loubo

Traslados de J. S. F. Rocha

Thesouro de meninos

Accidentes da infancia

Grammatica de Lobato

Grammatica de Martagão

Dos livros da distribuição do Governo existem em [...] no Conselho d'Instrução alguns exemplares da Theologia exegetica, e ensaio de Constituição Divina e o Cathecismo historico de Fleury, que S(ua) Ex(celênci)a mandou vir do Rio, e em tão pequeno numero, que não satisfazem à precisão das Escolas

B(ahi)a 21 de Fevereiro 1848

Justiniano da Silva Gomes

Presi(den)te do Conselho d' Instrucção

Interessante é que muitas dessas obras, que circularam na Bahia, também circularam em outras províncias. Segundo Tambara (2002, p. 39-40), os textos mais usados para o ensino da leitura, aqui no Brasil, no início do século XIX, foram principalmente o "Cathecismo Histórico" de Fleury e as Fábulas de Esopo. Depois foram substituídas pelo "Thesouro de meninos" de Blanchard, traduzida por Matheus José da Costa; e pelo Simão de Nantua de Jussieu. O "Thesouro de meninos" é uma obra clássica, dividida em três partes: Moral, Virtude e Civilidade. Em muitas edições foram agregados conteúdos mais técnicos e científicos. Essa foi uma tendência de meados do século XIX, agregar conteúdos, para conformar os livros, englobando praticamente todo currículo do ensino primário. Como exemplo, tem-se o "Manual enciclopédico" de Emílio Achiles Monteverde.

Dessa relação de livros de 1848, distribuídos às escolas na Província da Bahia, destaca-se a gramática de Martagão. Bernardino Affonso Martagão foi professor primário na Província da Bahia e teve sua gramática adotada, ao lado de outras, como se pode ver da relação das obras de 1848 . Essa gramática encontra-se no setor de obras raras da Biblioteca Universitária Reitor Macedo Costa da Universidade Federal da Bahia. É um livreto, contendo 59 páginas, cujo título é Compendio Rudimental de Grammatica da Lingua Potugueza: pelo professor publico Bernardino Affonso Martagão, segunda edição, 1880. 
Sabe-se, também, que Martagão era professor primário. No Relatório do Diretor Geral dos Estudos, Casemiro de Sena Madureira, dirigido ao Presidente da Província da Bahia, Francisco Gonçalves Martins, no ano de 1852, está dito que:

\begin{abstract}
Nenhum progresso faz a aula de que he Professor Bernardino Affonso Martagão depois que elle soffre de ophthalmia á ponto de parecer que tem se tornado chronica esta moléstia. Todavia o Professor dela não se queixa, talvez por não lhe fazer conta jubilarse antes de 20 annos de magistério; disto tenho dado noticia a V. Exa. em meos relatórios mensaes (MARTINS, 1854, p. 9).
\end{abstract}

Isso se leva a concluir que há mais de vinte anos essa gramática deveria ser utilizada nas escolas baianas.

Figura 1: Contracapa da gramática de Martagão.

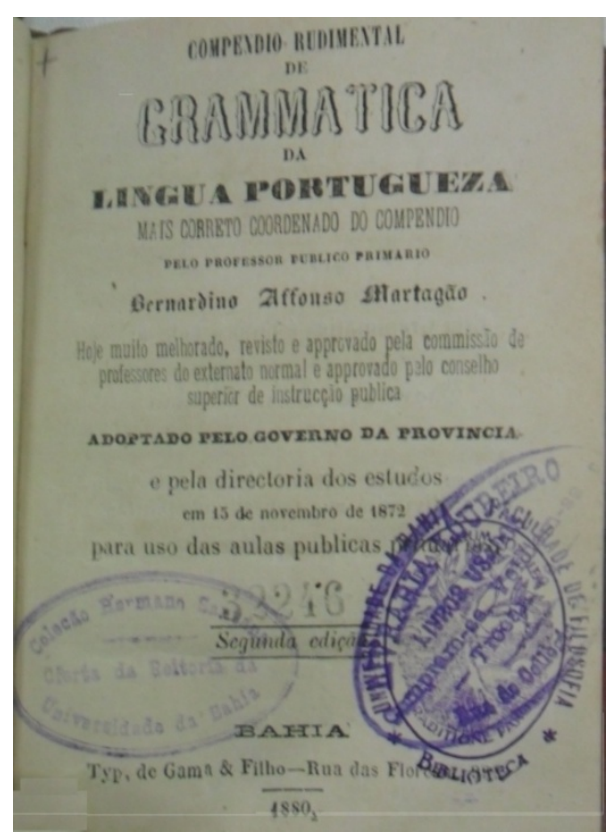

Pela contracapa (figura 1), ficam explicitadas as credenciais da gramática de Martagão: professor primário, e sua gramática, melhorada e revista, foi aprovada por instâncias superiores, que a qualificaram para ser adotada pelo governo da Província.

A gramática de Martagão possui o modelo das gramáticas filosóficas, de caráter lógico-racional, desenvolvidas nos séculos XVII e XVIII, e que predominaram até a primeira metade do século XIX, algumas adentrando a segunda metade do século.

Na Introducção, Martagão define gramática:

Grammatica é a arte que ensina a exprimir com acerto nossos pensamentos por palavras, quer fallando quer escrevendo.

Grammatica Portugueza é a arte que ensina a fallar, ler e escrever correctamente a língua portugueza.

Chama-se arte porque ensina os preceitos, e regras para bem ordenar a oração. (MARTAGÃO, 1880, p. 3) 
O uso da palavra arte, para definir a gramática, está no sentido dado por Aristóteles, na Metafísica, que é o de ofício, habilidade para se fazer algo. E este é o sentido usado na tradição grecolatina e nas gramáticas filosóficas dos séculos XVIII e XIX.

A gramática de Martagão é dividida em quatro partes: Ortographia, Etymologia, Syntaxe $e$ Prosódia, como são as gramáticas filosóficas. Segundo Fávero (2001, p. 65), essa divisão em quatro partes é herança da Idade Média, que permaneceu até o século XVI, com Nebrija e João de Barros, e vai até as gramáticas do século XIX, pelo menos da primeira metade.

Assim diz Martagão:

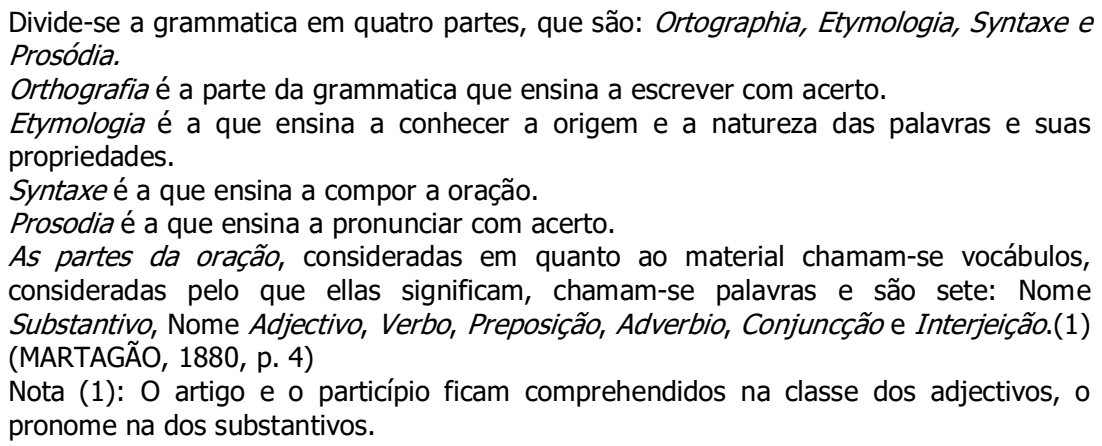

Essa é uma gramática que possui todas as divisões das gramáticas tradicionais, da Ortografia (e Fonética), da Pontuação, da Etimologia, (ou modernamente, da Morfologia), e da parte da Sintaxe, de forma bem condensada, com definições e poucos exemplos. É uma gramática não mitigada, pensando-se ser voltada para crianças do ensino elementar. Tudo é muito reduzido, a parte mais extensa diz respeito ao verbo, cujos paradigmas dos verbos auxiliares, regulares e irregulares são desenvolvidos. São apresentadas as formas simples e compostas.

Vão-se destacar algumas partes, de forma breve, as que estão em Souza (2015), e as que não estão. Na parte da ortografia, parece que não há separação entre a oralidade e escrita, haja vista que, na oralidade, essa diferença não é marcada, Más (adjetivo) e Mas (conjunção). No caso das três realizações do / e/, na última existe uma neutralização, no caso de átonas finais, o /e/ pronunciando-se [i].

\footnotetext{
A vogal a tem 2 sons, o $1^{\circ}$ longo e forte, como Más (adjectivo); o $2^{\circ}$ breve, como Mas (conjunç̧ão)

As vogais e e $o$, tem 3 sons: 10 longo e forte ou aberto, como: Fé, Dó, $2^{\circ}$ longo e brando ou fechado, como: Mercê, Avô; o $3^{\circ}$ mudo ou surdo, Mate, Cedo. (MARTAGÃO, 1880, p. 4)
}

Na parte da Etymologia, os substantives e os adjetivos estão inseridos na categoria maior do nome. Segundo Fávero e Molina (2006, p. 76), é uma concepção dos gramáticos greco-latinos, e a distinção substantivo e adjetivo é devido à escolástica. É essa divisão que está nas gramáticas contemporâneas. Na verdade, características morfossintáticas e semântico-discursivas os aproximam. 
Sobre os adjetivos, há os Determinativos e os Qualificativos. Fazem parte dos Determinativos, os artigos e pronomes (MARTAGÃO, 1880, p. 14):

\author{
Adjectivos \\ Os Determinativos são os que exprimem individualidades, como: os Artigos e os \\ Pronomes. \\ Os Pronomes são ou Pessoais, ou Possessivos, ou Relativos ou Demonstrativos. \\ (MARTAGÃO, 1880, p. 15)
}

Não só os adjetivos, artigos e pronomes são categorizados de forma diferente, nas gramáticas normativas contemporâneas; nessas, adjetivo, artigo e pronome, cada um constitui uma classe gramatical, também muda a forma de conceber. Quando o autor trata da formação do feminino, por exemplo, ele inclui os pronomes, ao lado dos adjetivos como: "[...] os acabados em 0 mudam o $o$ para $a$, como pequeno pequena. Exceptuam-se Judeu, Meu, Teu, Seu, Bom, que fazem Judia, Minha, Tua, Sua, Boa, Má." (MARTAGÃO, 1880, p. 17). Segundo Fávero e Molina (2006, p. 77), "Nas primeiras classificações das partes da oração, o pronome não se distinguia do artigo. Apolônio Díscolo dizia que o pronome designava objetos cuja qualidade se expressava indiretamente".

Em muitas gramáticas do século XIX, apenas os pessoais são considerados propriamente pronomes, os demais, embora pronomes se encontram na categoria dos adjetivos, como uma classe maior.

Martagão trata Da syntaxe (p. 45), discriminando a Oração, o Período, a Syntaxe da Regencia Regular, da Regencia Irregular pela Ellipse; Syntaxe de Concordancia Regular; Syntaxe de Concordancia irregular, pela Syllepse; Das Figuras da Syntaxe. O autor segue a tradição gramatical, identificada em outras gramáticas, como a de Frei Caneca.

Martagão trata das seguintes figuras da sintaxe: elipse, silepse, pleonasmo e hipérbato; segundo Fávero e Molina (2006, p. 79), esta é a classificação de Sánchez, na Minerva (1714).

Do que foi apresentado sobre a Sintaxe, vai-se destacar $A$ Syntaxe de Regencia Irregular pela Ellipse. Esse título significa que o uso da elipse, o que não foi dito, é o que torna a sintaxe irregular. Desdobrado o sintagma, ou desdobrada a frase é o que seria considerado o regular, como:

\footnotetext{
Verbo da oração sem sujeito. Exemplo: Estudo, Estudas, entende-se Eu estudo. Tu estudas

Quando o verbo transitivo se achar sem complemento objectivo, este se deve entender: Exemplo: Tendo de escrever; entende-se Tenho tenção ou resolução de escrever

Quando o complemento objetivo se achar sem verbo, este se deve entender: Exemplo: Bons dias; entende-se: Deus te de bons dias

Quando qualquer adjetivo se achar sem substantivo, os bons, as honestas, este se deve entender os homens bons, as mulheres honestas

Quando uma oração for expressa por um verbo no modo subjuntivo, deve-se entender outra no indicativo que determine. Exemp.: Deus guarde a V. S. entende-se Desejo ou peço à Deus que guarde a V. S. (MARTAGÃO, 1880, p. 46)
}

O que se compreende hoje, com os estudos linguísticos, é que o uso da elipse ou não, em qualquer construção sintática, constitui possibilidades que a língua oferece de comunicação. Todas as realizações são legítimas. Esses exemplos no nível sintático demonstram a realização ou não da norma 
padrão, estabelecida de acordo com os padrões normativos da época. As gramáticas contemporâneas, embora ainda apresentando grandes problemas em termos de descrição e prescrição, deixaram de estabelecer certas relações presentes nas gramáticas anteriores ao século XX.

\section{Considerações finais}

Pode-se ver, do que foi brevemente exposto, como se deu o processo de distribuição de livros às escolas públicas, quais eram os livros que se usavam nessas escolas, para a aprendizagem da leitura e da escrita, e o que liam, em especial no século XIX. Em termos de funcionamento da escola, se verifica que essas não eram devidamente aparelhadas, faltava o mínimo necessário para o seu funcionamento, como assentos e livros, dentre outras necessidades materiais. As Falas dos Presidentes da Província e os Relatórios de Diretores da Instrução Pública revelam o nível dessa precariedade.

Pelos livros que circulavam, vê-se uma grande maioria voltada para a formação moral, cívica e religiosa. Os processos de alfabetização e letramento, portanto, se davam num círculo limitado de possibilidades de leitura, e por que não de linguagem? Quanto ao exercício da leitura, essa se dava, em geral, pela memorização, via repetição. Sobre a escrita, nem todas as escolas a praticavam como deveriam, faltavam os instrumentos necessários, principalmente, na primeira metade do século XIX.

E o que dizer da aprendizagem da língua padrão, exposta pela gramática normativa, e de circulação nas escolas? Pela gramática de Martagão, se vê uma metalinguagem apresentada de forma objetiva em termos de descrição e regras de uso, bem compacta, cobrindo o essencial do modelo de gramática filosófica da época. Na verdade, pouco se sabe, ou quase nada se sabe de como se dava este estudo. $\mathrm{O}$ que ensinava o professor? Como essas regras eram apresentadas? O que aprendiam os alunos? A concepção de língua que transparece é fora dos padrões da língua em uso, em funcionamento. As regras da morfologia estão em paradigmas fechados; as regras da sintaxe, muito artificiais, considerandose que há uma sintaxe regular e outra irregular. Aqueles que aprenderam o padrão foram principalmente os que aprenderam em outros contextos, que não na maioria dessas escolas.

\section{Referências}

BARROS, Maria Cândida Drumond Disponível em: < http://www.academia.edu/4520970/Notassobre_os_catecismos_em_l\%C3\%ADnguas_vern\%C3\%A1culas_das _col\%C3\%B4nias_portuguesas_s\%C3\%A9culos_XVI_XVII>

BATISTA, Antônio Augusto G. Livros de leitura manuscrita: elementos para a história de um manual escolar. Comunicação oral apresentada no XXV Congresso Brasileiro de Ciências da Comunicação. Salvador/Ba, 2002.

CHARTIER, Roger. A história ou a leitura do tempo. 2 ed. 2reimp. Belo Horizonte - MG: Autêntica, 2016.

CHOPPIN, Alain. O manual escolar: uma falsa evidência histórica. Revista História da Educação. Rio Grande do Sul. v. 13, no 27, p. 9-75, enero-abril, 2009.

FÁVERO, Leonor L. A produção gramatical brasileira no século XIX - da gramática filosófica à gramática científica. In BARROS, Diana Luz P. (org.). Os discursos do descobrimento. São Paulo: FAPESP/EDUSP, 2001.

FÁVERO, Leonor L.; MOLINA, Márcia. As concepções linguísticas no século XIX: a gramática no Brasil. Rio de Janeiro: Lucerna, 2006.

JESUS, Tamires Alice Nascimento de. "Do pedido à mercê": investigação das correspondências sobre doação de livros às escolas públicas da Bahia no século XIX ou A instrução pública na Bahia oitocentista: o que revelam as 
correspondências sobre doação de livros às escolas públicas?2018, 160fl. Dissertação de Mestrado. Faculdade de Educação. Universidade Federal da Bahia. Salvador, 2018.

MARIGUELA, Adriana D. Bonine. A cartinha de João de Barros como um exercício de tradução. Revista Brasileira de Tradutores. Tradução \& Comunicação. Universidade Metodista de Piracicaba, no 23, p. 149-170. Piracicaba, 2011.

MARTAGÃO, Bernardino. Compendio Rudimental de Grammatica da Lingua Portuguesa. 2 ed. Salvador- Ba. Typ. Gama \&Filho, 1880.

ORLANDO, Evelyn de A. Os manuais de catecismo nas trilhas da educação: notas de história. Revista História da Educação (online). Porto Alegre. v. 17, no 41, set/dez, 2013.

OTA, Ivete Aparecida da S. O livro didático de língua portuguesa no Brasil. Educar, Curitiba n0 35, p. 211-221, Editora UFPR, 2009.

PINTO, Américo Cortez. Da famosa arte da imprimissão. Lisboa: Editora Ulisseia LTDA, 1948.

SILVA, José Carlos A. "A Nova Escola para Aprender a Ler, Escrever e Contar" (1722), cartilha para uso no ensino das primeiras letras nas escolas setecentistas do reino e das suas colônias. In II Encontro Internacional de História Colonial, 2008, Natal-Rn. ANAIS do II Encontro Internacional de História Colonial, Caicó - RN, 2008.

SOUZA, Antonio Wilson Silva. Manuais de caligrafia no Brasil do século XVIII: caminhos e concepções do desenho. In TRINCHÃO, Gláucia Maria C. (org.). Do desenho das belas letras à livre expressão no desenho da escrita. Salvador: EDUFBA, 2012.

SOUZA, Emília Helena Portella Monteiro de. Manuais de ensino de língua portuguesa na província da Bahia no século XIX. Revista Domínios de Lingu@gem. Uberlândia. MG. 40 trimestre, 2015, v. 9, no 4. P. 43-63.

TAMBARA, Elomar. Trajetórias e natureza do livro didático nas escolas de ensino primário no século XIX no Brasil. História da educação. Pelotas: ASPHE/FaE/UFPel.,2002. p. 25-52.

TRINDADE, Carolina Antonia S. Escolarizar para civilizar: o Recolhimento de Nossa Senhora dos Humildes em Santo Amaro da Purificação - Bahia, século XIX. 2018. 192 fl. Dissertação de Mestrado. Instituto de Letras. Universidade Federal da Bahia. Salvador, 2018.

\section{Fontes}

APEB. Fundo Instrução Pública. Maço: 1039. Presidência da Província Instrução Pública. Compendios Didacticos, 1868-1876.

APEB. Catálogo Arquivos Coloniais e Provinciais. Inventário dos documentos da província. Outros Fundos. $3^{a}$ Parte. Instrução Pública. Série Educação. Documento n 6051, Relatórios da Diretoria Geral dos Estudos e Presidência da Província, p. 70.

APEB. Livro de lançamento de entrada e saída de livros fornecidos as escholas publicas. 1880. Catálogo Arquivos Coloniais e Provinciais. Inventário dos Documentos da Província. Outros Fundos - 3a. Parte. Instrução pública. série Educação. Código de registro: 6566-1.

Falla que recitou o presidente da provincia da Bahia, João José de Moura Magalhães, na abertura da Assembléa Provincial da mesma provincial no $1^{\circ}$ de março de 1848. Bahia, Typ. Constitucional de Vicente Ribeiro Moreira, 1848. Disponível em www.apps.crl.edu/brazil/provincial/bahia. Acesso em 05 set. 2018.

Falla com que o exm. sr. Francisco Gonçalves Martins abriu a $1^{a}$ sessão da vigésima legislatura da Assembléa Legislativa Provincial, no dia 10 de março de 1850. Bahia Typ. do Correio da Bahia, 1850. Disponível em www.apps.crl.edu/brazil/provincial/bahia. Acesso em 05 set. 2018.

Falla com que o exm. sr. Antonio Candido da Cruz Machado abriu a $1^{a}$ sessão da vigésima legislatura da Assembléa Legislativa Provincial, no dia $1^{0}$ de março de 1874. Bahia Typ. do Correio da Bahia, 1874. Disponível em www.apps.crl.edu/brazil/provincial/bahia. Acesso em 05 set. 2018.

Relatório com que o excelentíssimo senhor dr. Justiniano da Silva Gomes, abrio a $2^{\mathrm{a}}$ sessão da $20^{\mathrm{a}}$ legislatura da Assembléa Legislativa Provincial no dia $1^{0}$ de março de 1846. Typ. do Jornal da Bahia, 1854. Disponível em www.apps.crl.edu/brazil/provincial/bahia. Acesso em 05.set. 1846.

Relatório com que o excelentíssimo senhor dr. Casimiro de Sena Madureira, abrio a $2^{a}$ sessão da $20^{a}$ legislatura da Assembléa Legislativa Provincial no dia $1^{0}$ de março de 1854. Typ. do Jornal da Bahia, 1854. Disponível em www.apps.crl.edu/brazil/provincial/bahia. Acesso em 05.set. 1854.

Relatório com que o (excelentíssimo) diretor da Instrução Públicadr Francisco José da Rocha, abriu a sessão da Assembléa Legislativa Provincial no dia $1^{0}$ de maio de 1872. Bahia Typ. do Correio da Bahia, 1872. Disponível em www.apps.crl.edu/brazil/provincial/bahia. Acesso em 05 set. 2018.

Relatório com que o excelentíssimo senhor presidente da província, José Eduardo Freire de Carvalho, abriu a sessão da Assembléa Legislativa Provincial no dia $1^{\circ}$ de maio de 1876. Bahia Typ. do Correio da Bahia, 1876. Disponível em www.apps.crl.edu/brazil/provincial/bahia. Acesso em 05 set. 2018. 